\title{
Ancient medical schools in Knidos and Kos
}

\author{
Mehmet Turgut
}

Published online: 25 August 2010

(C) Springer-Verlag 2010

The long history of medicine begins with the ancient schools of Knidos and of Kos, referring to the systems of knowledge produced by great personalities [1]. It is interesting to note that the two places where medical thought was born, the island of Kos in Greece and the peninsula of Knidos in Turkey, were both in the same geographic region and appeared over the horizon at about the same time (Fig. 1; http://www.hapimag-seagarden. com/images/location/Bodrum\%20overall\%20mapB.jpg) [2].

The medicine which arose in the two famous ancient medical schools in that small corner derived knowledge from many older sources such as Egyptian and Mesopotamian civilisations [3]. There was a nice competition between the two ancient medical schools and many physicians studied in these schools, such as Praxagoras of Kos and his student Herophilus, Chrysippus of Knidos and his student Erasistratus (http://www.ishm2006.hu/scientif ic/abstract.php?ID=52). Hippocrates (460-377 BC), a great physician known as the father of medicine, received his initial training and then he established his medical school in the island of Kos (http://www.arehna.di.uoa.gr/ Kos_history.htm).

M. Turgut $(\bowtie)$

Department of Neurosurgery, Adnan Menderes University School of Medicine,

09100 Aydın, Turkey

e-mail: drmturgut@yahoo.com
The main difference between the ancient medical school of Knidos and that of Kos lies in the fact that the former was interested in "local" character of disease and the latter was more interested in "general" character of disease [4, 5]. In other words, the physicians of Kos are related with general medicine, while their Knidian colleagues dealt with medical specialities. In Knidos, diseases were classified according to the organ affected and Knidian physicians recognised seven diseases of the bile and 12 of the bladder (http://asclepieion.mpl.uoa.gr/parko/ marketos2.htm). Thus, Knidian medicine concentrated on the "disease" rather than on the patient, while Hippocratic medicine of Kos emphasised the "patient" rather than the disease, with a great attention to the evaluation of the physical findings [2-5].

The Asclepieion of Kos is the famous Sanctuary of Asclepios, the son of the God Apollo and the father of a large family including famous surgeons such as Podalirius and Machaon, which dates from the fourth century $\mathrm{BC}$ and was built on the site of a still older temple to Apollo [6]. The Hippocratean medical school, Asclepieion, had become the most famous medical centre of the Graeco-Roman Antiquity (Figs. 2 and 3; http://www.nwotsok.nl/asklepion). It was discovered by the German archaeologist Rudolf Herzog in 1901 and was then systematically excavated by the Italians [4, 5]. The illustration on the cover of Child's Nervous System depicts oblation of a patient having his leg cured (Fig. 4; http://www.arehna.di.uoa.gr/Kos_history. htm). 
Fig. 1 A map showing the geographical locations of the oldest hospitals in the world (http://www.hapimag-seagarden. com/images/location/Bodrum $\%$ 20overall\%20mapB.jpg)
Fig. 2 A drawing illustrating restoration of the school of medicine of Kos, known as Asclepieion, during the Hellenistic period. Reprinted with permission of Nwotsok, The Netherlands (http://www. nwotsok.nl/asklepion/plan.jpg)
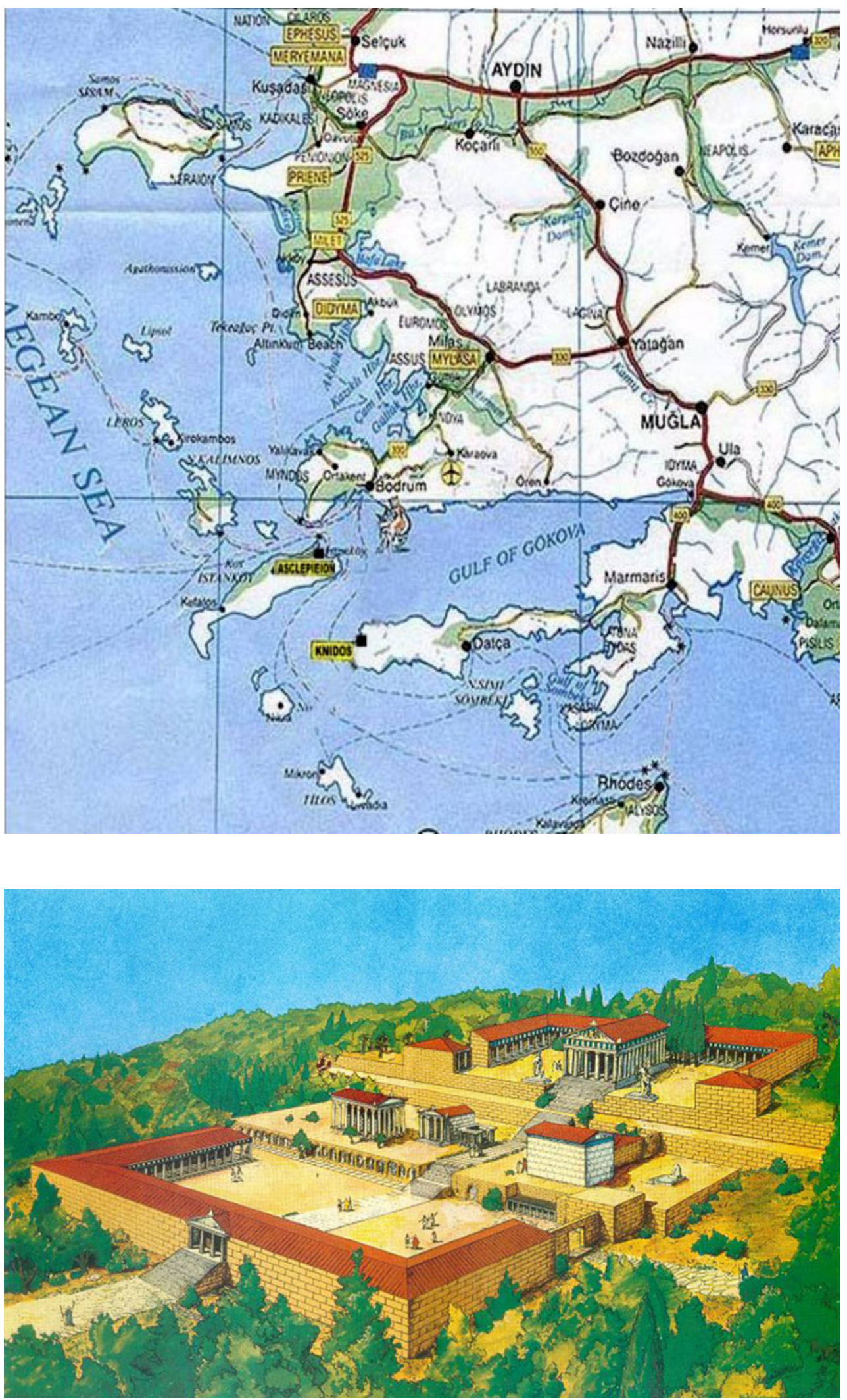
Fig. 3 A sketch demonstrating Asclepieion during the Hellenistic period. Reprinted with permission of Nwotsok, The Netherlands (http://www. nwotsok.nl/asklepion/map.jpg)

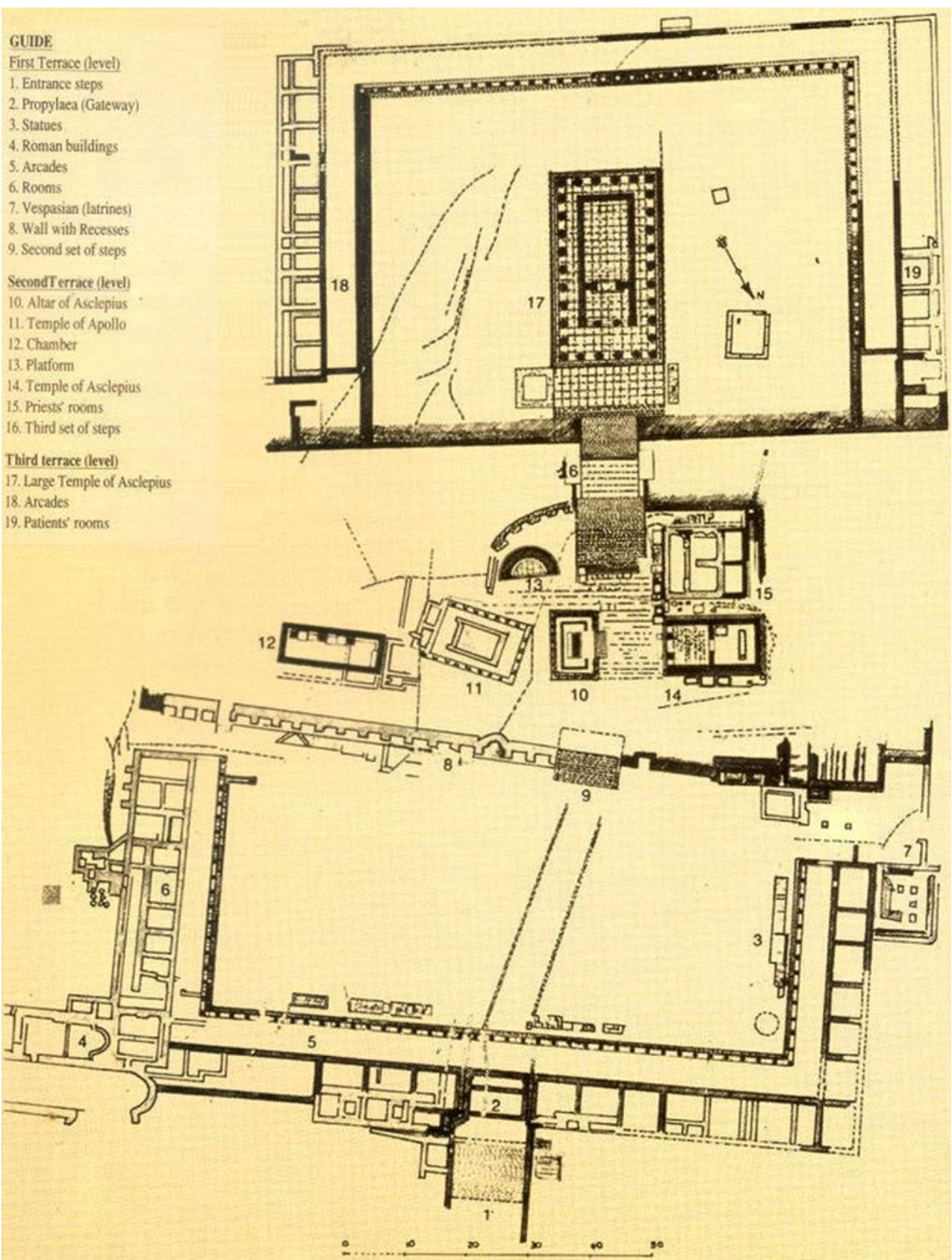

According to Hippocrates, human beings are made of a body, which contain four humours corresponding to the four organs of the body (the heart, the brain, the liver and the spleen). The disequilibrium of the four humours produces disease [3]. According to Hippocrates, "the brain is the most powerful organ of the human body" (http://asclepieion.mpl.uoa.gr/parko/marketos 2.htm).
Today, various modifications of Hippocrates' surgical techniques are still used in the medicine and modern surgery, including paediatric neurosurgery. More importantly, any kind of surgical intervention was prohibited in certain situations, known as the Hippocratian dogma "to help or at least not to harm" (http://asclepieion.mpl.uoa.gr/ parko/marketos2.htm). 


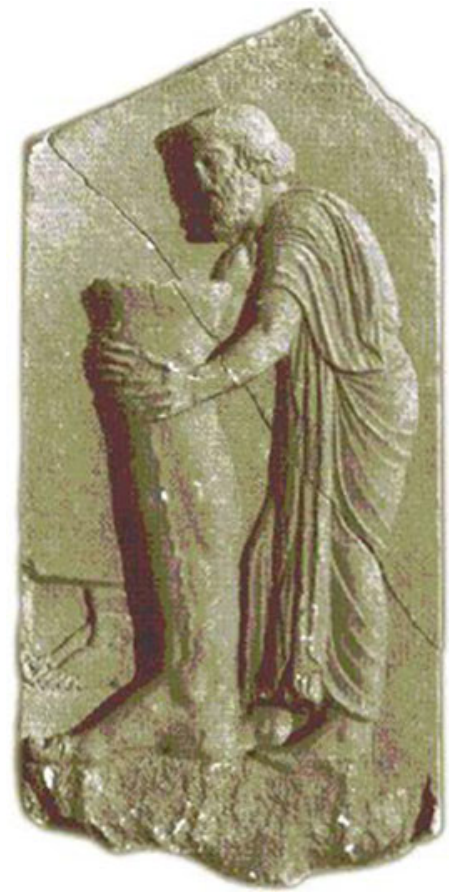

\section{References}

1. Longriff J (1989) Presocratic philosophy and hippocratic medicine. Hist Sci 27:1-39

2. Smith WD (1973) Galen on Coans versus Cnidians. Bull Hist Mad 47:569585

3. Marketos SG (1993) Hippocrates the Koan: the father of rational medicine. Springer Japan Publishing Inc., Tokyo

4. Gibson WS (1966) Hippocrates' home. JAMA 1966(197):628-631

5. Sakula A (1984) In search of Hippocrates: a visit to Kos. J R Soc Med 77:682-688

6. Bailey JE (1996) Asklepios: ancient hero of medical care. Ann Intern Med 124:257-263

Fig. 4 The cover picture illustrates a drawing depicting the oblation of a patient having his leg cured from The Asclepieion of Kos. Reprinted with permission of project coordinator Associate Prof. of Environmental Pathology P. Nicolopoulou Stamati from AREHNASANCO project www.arehna.di.uoa.gr (http://www.arehna.di.uoa.gr/ Kos_history.htm) 